\title{
Heterogeneidade nos níveis de actividade física de crianças dos 6 aos 12 anos de idade. Um estudo em gémeos
}

\author{
José A.R. Maia ${ }^{1}$ \\ Rui Garganta ${ }^{1}$ \\ André Seabra ${ }^{1}$ \\ Vítor P. Lopes ${ }^{2}$
}

\section{https://doi.org/10.5628/rpcd.04.01.39}

\section{RESUMO}

Esta pesquisa pretende estabelecer a importância dos efeitos genéticos e do envolvimento na heterogeneidade dos valores de actividade física, em crianças com idades compreendidas entre os 6 e os 12 anos de idade. Com base numa amostra de 101 pares de gémeos monozigóticos e dizigóticos, foram estimadas as magnitudes das variâncias devidas a efeitos genéticos e do envolvimento nos níveis de actividade física, avaliados a partir do questionário de Godin e Shephard (11), depois de removidos os efeitos das covariáveis idade e sexo. Recorreu-se aos procedimentos habituais em estudos gemelares, como sejam o cálculo da correlação intra-classe (t) e da heritabilidade $\left(\mathrm{h}^{2}\right)$. Foi utilizado o software Systat 10. Os principais resultados e conclusões sugerem: (1) o valor baixo de $\mathrm{h}^{2}$ na actividade física ligeira $(34 \%)$ e intensa $(24 \%)$, implicando que cerca de $1 / 4$ das diferenças inter-individuais nos níveis de actividade física sejam devidas a efeitos genéticos; (2) o valor elevado da influência do envolvimento comum (familiar, amigos, professores e outros significantes), i.e., de $66 \%$ a $82 \%$, e que remete para os pais, amigos e professores (de Educação Física e outros) um fortíssimo papel pedagógico na implementação de hábitos moderados a intensos de actividade física e estilos de vida mais saudáveis.

Palavras-chave: heterogeneidade, gémeos, actividade física, genética, envolvimento, crianças.

\author{
${ }^{1}$ Faculdade de Ciências do Desporto e de Educação Física \\ Universidade do Porto \\ ${ }^{2}$ Instituto Politécnico de Bragança, Portugal
}

\begin{abstract}
Heterogeneity in Physical Activity Levels in Children Aged 6 to 12 Years Old. A Twin Study

This study aims at the identification of the magnitude of genetic and environmental effects in the heterogeneity of physical activity of children (aged 6 to 12 years). Based on a sample of 101 monozygotic and dizygotic twin pairs, the magnitudes of genetic and environmental factors were estimated. The Godin \& Shephard questionnaire (11) was used and the effects of such covariates as gender and age were removed from all calculations. We used habitual procedures in twin data analysis, such as intraclass correlations $(t)$ and heritability estimates $\left(h^{2}\right)$. Systat 10 was used in all calculations. Main results and conclusions suggest: (1) the low values of $h^{2}$ in low-to-moderate physical activity level (34\%), and high level of physical activity (24\%), although, altogether, genetics factors account for 1/4 of the total variation; (2) the high estimate of common environment (family, friends, teachers and significant others), i.e., $66 \%$ to $82 \%$. This calls for a strong influence of parents, teachers and friends in their relevant role in the moderateto-high physical activity habits and a healthy life-style of children.
\end{abstract}

Key Words: heterogeneity, twins, physical fitness, genetics, environment, children. 


\section{INTRODUÇÃO}

Estudos de natureza epidemiológica têm demonstrado uma associação forte e consistente entre actividade física, aptidão física e saúde (sobre esta matéria consultar o volume da conferência de Toronto realizada em 1992 - 4). As recomendações do Centro de Controlo de Doenças dos USA, da Associação Americana de Cardiologia, do Colégio Americano de Medicina Desportiva, da Organização Mundial de Saúde e da Associação Portuguesa de Cardiologia relativamente à importância da actividade física na redução dos factores de risco de doenças cárdio-vasculares, obesidade, hipertensão, osteoporose, níveis elevados de colesterol e depressão mostram, pela primeira vez na história da Epidemiologia e Saúde Pública, a relevância inegável da actividade física e prática desportiva.

A actividade física regular e culturalmente referenciada, de forte carácter lúdico, psicologicamente significante e socialmente relevante, é considerada como um "medicamento" de eficácia comprovada em diferentes tipos de morbilidade e, nalgumas circunstâncias, encontra-se fortemente associada à longevidade $(2,4,28)$.

Hábitos, comportamentos e atitudes descritores de um estilo de vida saudável e activo, condicionadores da redução dos factores de risco nefastos para o indivíduo tendem a desenvolver-se cedo, no seio da família, agente fulcral de socialização e ensino-aprendizagem de uma educação esclarecida para a saúde $(12,17)$. É forte a crença entre epidemiologistas (33) e especialistas em Ciências do Desporto (1, $15,22,23,38)$ de que a infância representa um período óptimo de "imprint" de hábitos e comportamentos de saúde, bem como do desenvolvimento de um estilo de vida activo que se espera venha a manter-se durante o curso posterior da vida do sujeito. Se a promoção do desporto e da actividade física regular serve propósitos fortemente preventivos em termos de saúde pública (34), e se os comportamentos de saúde (i.e. estilos de vida saudáveis) são parte integrante da matriz sócio-cultural (12), então é da maior importância identificar as relações primárias que se estabelecem no seio de famílias nucleares (enquanto instituição social de primeiríssima ordem) na transmissão de hábitos desportivos e de actividade física.
É inequívoca a presença de uma forte variação no tipo, duração, frequência e intensidade dos valores da actividade física habitual em crianças, jovens e adultos. Entre os apreciadores de pipocas, batatas fritas, sofá e televisão e os triatletas, corredores de fundo e outras provas de longa duração situa-se uma enorme dispersão que parece comportar-se de acordo com a distribuição normal.

Os valores da actividade física são um fenótipo quantitativo contínuo de natureza complexa e multifactorial, onde é evidente a presença de dois grandes agentes causais - os genes e o envolvimento. A análise deste fenótipo, em termos populacionais, tem sido efectuada a partir de posições normativistas a que se associa a "forte tirania" da interpretação centrada exclusivamente nos valores das médias (3). Afinal qual é o significado da média, qual a sua relevância em termos interpretativos do comportamento dos valores da actividade física no seio da população? No coração da pesquisa diferencialista, o pulsar central da sua atenção é voltado para o estudo da variação. A medida que caracteriza com maior rigor aquilo que ocorre a nível populacional. Tal como referimos anteriormente, a variação é devida a dois grandes agentes causais: variação na sequência de DNA, fenómenos de epistasia (interacção entre genes), co-acção entre genes (fenómeno de pleiotropia, i.e., acção de um gene em diferentes fenótipos), diferenciação nos estilos de vida e noutros factores do envolvimento, que interessa interpretar quando se lida com informação onde é bem evidente uma forte heterogeneidade de resultados.

Uma resposta tendente à elucidação da variância presente no fenótipo actividade física tem de ser encontrada, também, no domínio biológico através de um delineamento sequencial de pesquisa (para mais detalhes ver $3,16,31$ ) de que destacamos as seguintes fases: (a) a identificação da presença de agregação familiar nos hábitos de actividade física em famílias nucleares, ou em gémeos; (b) a identificação do quanto da variação da actividade física é causada por diferenças genéticas entre os sujeitos; (c) o estudo de três ou quatro gerações, ou simplesmente pares de irmãos, para identificar, a partir de marcadores genéticos adequados, em que zonas específicas dos cromossomas se situam os genes de efeitos aditivos no fenótipo em causa (i.e. os quantitative trait loci), e 
finalmente (d) a localização dos genes e o esclarecimento dos seus mecanismos de acção.

É evidente que a pesquisa que iremos apresentar situa o seu alcance exclusivamente nos pontos a e b, no seio do paradigma da Epidemiologia Genética, dado que, até ao momento, os pontos c e d ainda não foram objecto de qualquer investigação publicada no domínio da Biologia Molecular ou

Epidemiologia Genética em humanos.

A outra parte da variância fenotípica tem que ser explicada por mecanismos de natureza sócio-cultural. É um facto conspícuo que os progenitores não transmitem aos seus descendentes exclusivamente genes, bem pelo contrário. No seio familiar são passados aos descendentes hábitos, atitudes e valores culturalmente aceites numa dada sociedade e estrato social, no que à actividade física e ao desporto dizem respeito. Contudo, há que mencionar que as crianças são também permeáveis a um tipo de influências únicas do seu envolvimento exclusivo, e que contém tudo aquilo que não é influência parental. Este estudo tem um duplo propósito: (a) apresentar, ainda que de forma tangencial, aspectos nucleares do domínio da Epidemiologia Genética em estudos gemelares ${ }^{1}$ aplicados à investigação da variação nos níveis de actividade física de crianças e, (b) tentar estabelecer a magnitude e importância dos grandes agentes influenciadores das diferenças interindividuais nos níveis de actividade física. Estes propósitos afiguram-se-nos importantes por dois motivos: o primeiro prende-se com a necessidade em apresentar aspectos básicos de estudos gemelares e sua importância aos investigadores das Ciências do Desporto dos países de língua oficial portuguesa (ver também 23, 24, 27); o segundo associa-se ao facto de ser praticamente inexistente qualquer pesquisa com amostras gemelares dos seis aos doze anos de idade, e que pretenda esclarecer o quanto da variação presente nos valores da actividade física é devido a efeitos genéticos e quanta é implicada aos efeitos do envolvimento.

\section{METODOLOGIA}

\section{Aspectos essenciais}

Para se perceber a complexidade de qualquer traço ou característica métrica que interessa aos investigadores das Ciências do Desporto procuraremos mostrar, a partir de um simples exemplo ilustrado na Figura 1, a complexidade da combinação de influências genéticas e do envolvimento, bem como a sua interacção no que ao dispêndio energético total diário diz respeito, sobretudo a faceta que mais nos interessa - a actividade física.

Genericamente, a actividade física é entendida como qualquer movimento produzido pelos músculos

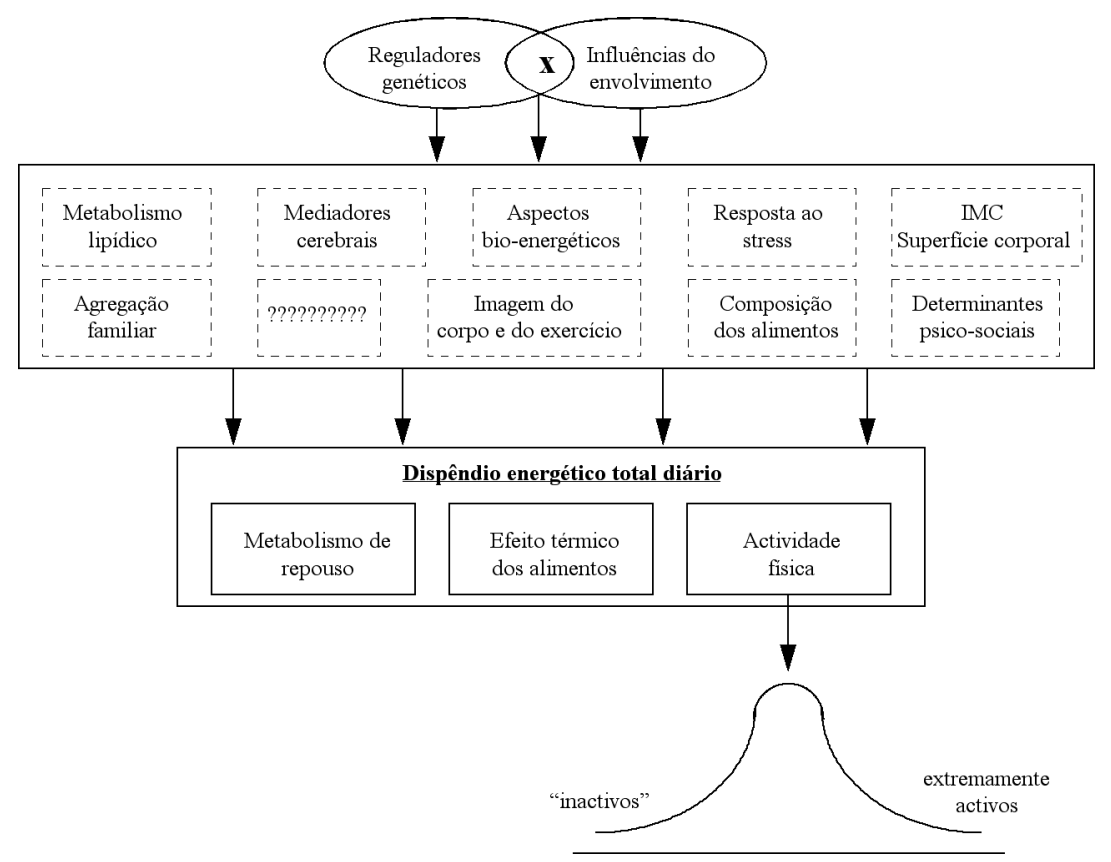

Figura 1: Estrutura multifactorial hipotética da complexidade do fenótipo actividade física. esqueléticos e que resulta em dispêndio energético, para além do metabolismo de repouso (5). Se considerarmos o dispêndio energético total diário (DETD), fácil é constatar que é constituído por três partes: 
- Metabolismo basal + "arousal", que corresponde ao metabolismo de repouso, compreendendo cerca de $70 \%$ do DETD, embora apresente forte variação inter-individual e seja condicionado, em certa medida, por factores de natureza genética. Ver, por exemplo, Fontaine e colaboradores (9).

- Termogénese induzida pela digestão e assimilação dos alimentos (cerca de 10\% do DETD).

- Actividade física diária, que é, sem qualquer sombra de dúvida, a fatia do DETD que maior variação apresenta no seio de qualquer população.

No domínio aplicado à investigação da actividade física, as etapas interrogativas deste olhar podem ser apresentadas do seguinte modo (mais detalhes podem ser encontrados em 3 e 31), e são ilustradas na Figura 2:

a. Será que os níveis de actividade física tendem a evidenciar agregação ou semelhança no seio de famílias nucleares? Isto é, será que os valores de actividade física tendem a transmitir-se dentro das famílias?

b. Será possível quantificar, de modo válido e preciso, a variância na actividade física no seio da população, e determinar o quanto é devido à circunstância dos sujeitos serem geneticamente diferentes? Isto é, quanta variância observada é devida a efeitos genéticos?

c. Depois de quantificada a presença de efeitos genéticos, i.e., o cálculo da heritabilidade, a questão seguinte trata da identificação de zonas de cromossomas onde se alojarão os genes responsáveis por tal variação.

d. Uma vez localizadas as zonas e os genes, bem como os seus produtos, genericamente proteínas estruturais e de regulação, a etapa seguinte é descrever os mecanismos pelos quais os genes e os seus produtos explicam as diferenças na expressão populacional do fenótipo actividade física.

e. Uma etapa complementar, mas também da maior importância, é a que trata de interpretar a interacção dos mecanismos genéticos com os do ambiente na variação existente na actividade física no seio populacional.

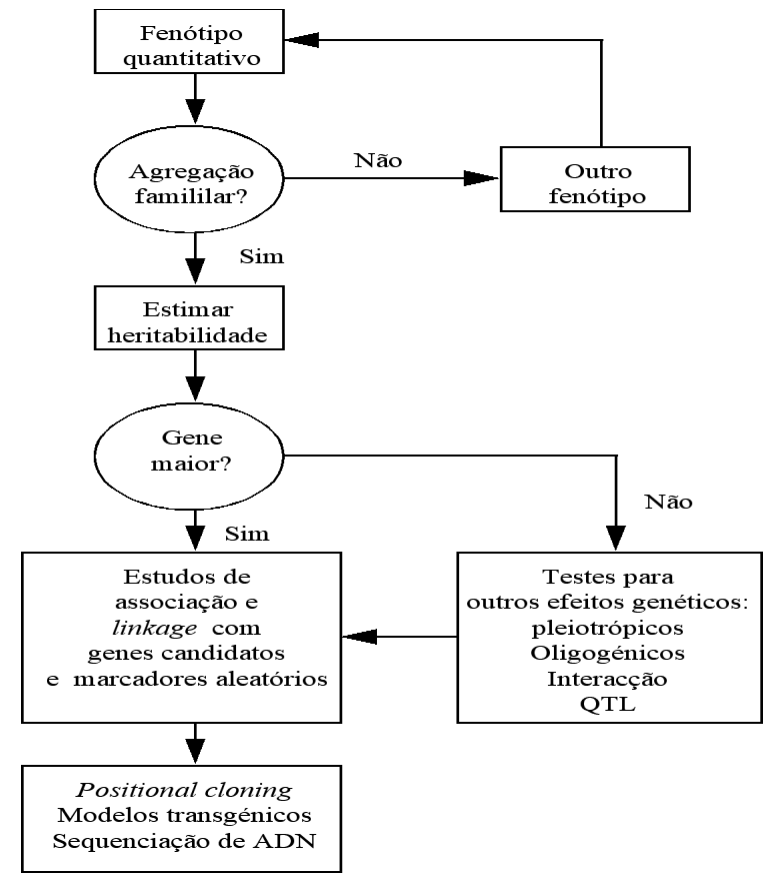

Figura 2: Sequência de etapas da pesquisa em Epidemiologia Genética para investigar fenótipos complexos (redesenhado de Bouchard et al. - 3).

É evidente que a realização de uma tarefa desta envergadura, sobretudo no que se refere à complexidade, profundidade e extensão, ainda se encontra na sua infância (uma visão actual desta tarefa é encontrada em 3, 31). Daqui que nos centremos somente nos pontos $a \mathrm{e} b$, aqueles onde existe informação que permite interpretar os resultados que a seguir apresentaremos.

\section{Aspectos do delineamento gemelar}

No lato território do delineamento gemelar, localizado na metodologia Top-Down (sobre esta matéria consultar Bouchard et al. - 3), interessa considerar um conjunto importante de pressupostos $(8,16,20)$ : (a) os pares de gémeos são da mesma idade e partilham o mesmo envolvimento familiar de origem (i.e. possuem o mesmo envolvimento comum); (b) os gémeos $\mathrm{MZ}$ partilham os mesmos factores genéticos (os mesmos alelos em cada locus). Os gémeos DZ partilham somente metade dos genes, tal como o que ocorre entre irmãos; (c) um envolvimento semelhan- 
te afecta gémeos $\mathrm{MZ}$ e gémeos $\mathrm{DZ}$; (d) a comparação da similaridade entre gémeos $\mathrm{MZ}$ e gémeos $\mathrm{DZ}$, relativamente a um fenótipo, permite identificar as fontes de variação na população - genes, envolvimento comummente partilhado e envolvimento único.

No modelo clássico, qualquer fenótipo é constituído por duas componentes aditivas - uma genética $(G)$ e outra do envolvimento (E). Quando se pensa em termos populacionais, no modelo clássico em Genética Quantitativa, a variância fenotípica total $\left(\mathrm{V}_{\mathrm{TOT}}\right)$ de qualquer traço contínuo pode ser fraccionada em dois tipos de variância - a variância genética $\left(\mathrm{V}_{\mathrm{G}}\right)$ e a variância do envolvimento $\left(\mathrm{V}_{\mathrm{E}}\right)$. A variância do envolvimento pode ser ainda fraccionada em duas outras fontes de variação - a que é devida ao envolvimento comummente partilhado no seio da família $\left(V_{C}\right)$ e a que é específica e única de cada par $\left(\mathrm{V}_{\mathrm{ESP}}\right)$.

Da comparação destas fontes de variação, é possível calcular uma rácio designada de heritabilidade $\left(\mathrm{h}^{2}\right)$ que se refere à proporção de variância total que pode ser atribuída a efeitos genéticos $\left(\mathrm{h}^{2}=\mathrm{V}_{\mathrm{G}} / \mathrm{V}_{\mathrm{TOT}}\right)$. De um modo semelhante, podem calcular-se a contribuição dos factores do envolvimento comum $\left(c^{2}=V_{C} / V_{\text {TOT }}\right)$ e dos factores específicos $\left(\mathrm{e}^{2}=\mathrm{V}_{\mathrm{ESP}} / \mathrm{V}_{\text {TOT }}\right)$.

Nestas formulações do modelo clássico, é imperioso que se cumpram quatro pressupostos fundamentais $(8,16,20)$ : (a) ausência de interacção dos genótipos com o envolvimento (isto significa que diferentes genótipos reagem de modo similar aos mesmos factores do envolvimento, traduzindo uma igualdade de susceptibilidade); (b) ausência de correlação entre genótipos e envolvimento (isto quer dizer que os vários genótipos são expostos a condições semelhantes do envolvimento); (c) ausência de interacção gene-gene (i.e. não se verifica epistasia) e; (d) ausência de acasalamento preferencial.

Para se interpretar e esclarecer o significado de similaridade intra-par quando o traço em estudo é quantitativo contínuo vamos servir-nos da Figura 3 e dos diferentes resultados do coeficiente de correlação esperados entre membros do mesmo par.
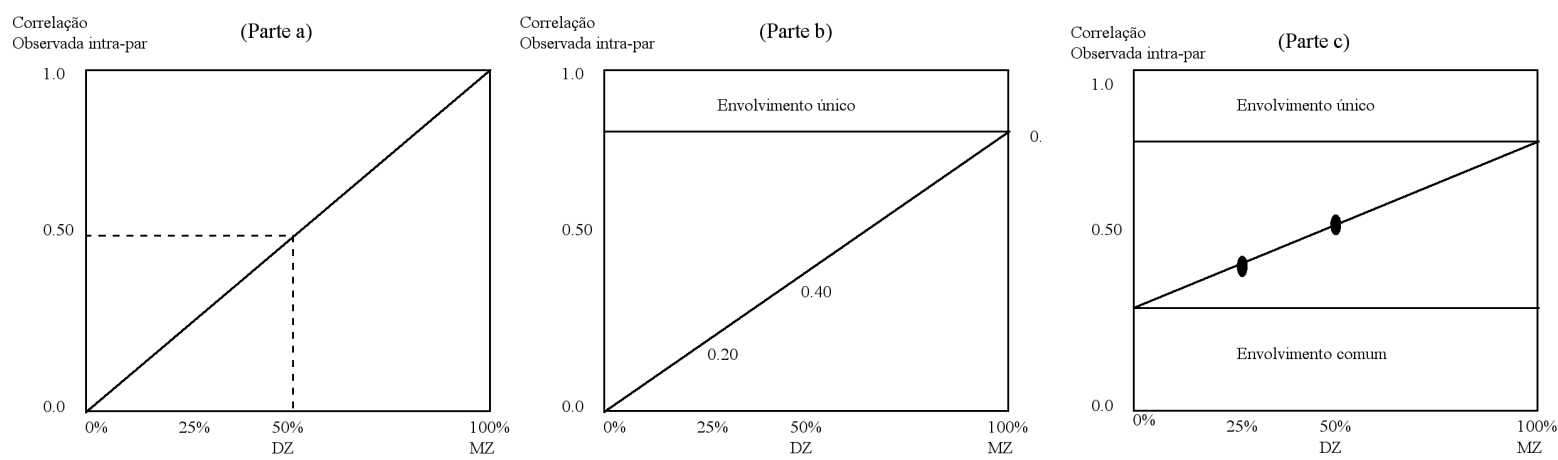

Figura 3: Representação esquemática dos diferentes valores esperados, em teoria, da correlação intra-par.

- Parte a: quando estamos na presença exclusiva de efeitos genéticos aditivos, os valores esperados (i.e. teóricos) para as similaridades intra-par são os seguintes: gémeos $\mathrm{MZ}=100 \%$; gémeos $\mathrm{DZ}$, irmãos ou pai-filho(a), mãe-filha(o) $=50 \%$; primos ou avô-neto $=25 \%$, e na população o valor é $0 \%$.

- Parte $b$ : se a similaridade não é perfeita, por exemplo se o valor de $r_{M Z}=0.80$, mas a similaridade nos outros pares segue uma relação proporcional de acordo com as rácios da relação genética, $\mathrm{r}_{\mathrm{DZ}}=0.40$ e avô-neto, $\mathrm{r}=0.20$, dois factores são causadores da variação fenotípica - factores genéticos aditivos e factores do envolvimento únicos do sujeito. No caso dos gémeos $\mathrm{MZ}$, considerando o fenótipo $\mathrm{X}$, se o $\mathrm{r}_{\mathrm{MZ}}=0.80$ tal significa que 
$80 \%$ da variação no fenótipo é devida a efeitos génicos e $20 \%$ ao envolvimento único do sujeito.

- Parte c: se a similaridade nos pares for maior do que o esperado, de acordo com o modelo teórico $\left(\mathrm{r}_{\mathrm{MZ}}<2 \mathrm{r}_{\mathrm{DZ}}\right)$, então parte da variação no fenótipo é devida, também, a factores comuns do envolvimento.

O coeficiente de correlação intra-classe ( $t$ ) é uma estatística que indica o grau de homogeneidade de uma classe de valores, esperando-se que a classe dos gémeos $\mathrm{MZ}$, para um qualquer traço métrico, seja sempre mais homogénea que a classe dos gémeos $D Z$. Daqui que o valor $t_{M Z}$ deva ser sempre superior ao $t_{\mathrm{DZ}}$. O coeficiente de correlação intra-classe é obtido a partir da análise de variância (ANOVA). Neste procedimento estatístico deve dar-se especial atenção à "variação" intra-par nos gémeos MZ (Mean Square Within ${ }_{\mathrm{MZ}}$ ) e nos gémeos DZ (Mean Square Within $_{\mathrm{DZ}}$ ). Espera-se que a "variação" intra-par DZ seja superior à "variação" intra-par MZ.

\section{Estimativa de heritabilidade (h2)}

Com base nos valores dos coeficientes de correlação de Pearson ou da correlação intra-classe, é possível estimar uma quantidade designada por heritabilidade, que representa o quanto da variância observada $\left(\mathrm{V}_{\text {TOT }}\right)$ é devida à variância genética $\left(\mathrm{V}_{\mathrm{G}}\right)$, ou a diferenças genéticas inter-individuais. Daqui que esta estimativa seja genericamente representada por: $\mathrm{h}^{2}=$ $\mathrm{V}_{\mathrm{G}} / \mathrm{V}_{\mathrm{TOT}}$.

Como lidamos com gémeos $\mathrm{MZ}$ e $\mathrm{DZ}$, em que os gémeos $\mathrm{MZ}$ partilham os mesmos genes e o mesmo envolvimento comum (são cópias um do outro), e os gémeos $\mathrm{DZ}$ partilham, em média, metade dos genes e o mesmo envolvimento comum, as correlações esperadas em cada zigotia são, pois:

$\mathrm{r}_{\mathrm{MZ}}=\mathrm{h}^{2}+\mathrm{c}^{2}$

$\mathrm{r}_{\mathrm{DZ}}=1 / 2 \mathrm{~h}^{2}+\mathrm{c}^{2}$

Se subtrairmos os dois valores de correlação, obteremos $\mathrm{h}^{2}=2\left(\mathrm{r}_{\mathrm{MZ}}-\mathrm{r}_{\mathrm{DZ}}\right)$.

Dado que a variância total é fixada em 1, e que é composta de forma aditiva pela variância genética $\left(\mathrm{h}^{2}\right)$ do envolvimento comum $\left(\mathrm{c}^{2}\right)$ e do envolvimento único $\left(\mathrm{e}^{2}\right)$, obtem-se

$h^{2}+c^{2}+e^{2}=1$ que, de acordo com regras simples de álgebra, permite obter

$\mathrm{e}^{2}=1-\mathrm{r}_{\mathrm{MZ}}$

$\mathrm{C}^{2}=2 \mathrm{r}_{\mathrm{DZ}}-\mathrm{r}_{\mathrm{MZ}}$

Com base nestas regras simples, é possível estimar as quantidades mais relevantes da variação observada.

\section{Amostra}

A amostra foi constituída por 32 pares de gémeos MZ (idade $=8.26 \pm 1.61$ anos; 6 aos 12 anos), 16 do sexo masculino e 16 do sexo feminino; 69 pares de gémeos DZ (8.96 \pm 1.51 anos; 7 aos 12 anos), 22 do sexo masculino, 14 do sexo feminino e 33 de sexo oposto.

\section{Actividade física}

A avaliação da ActF foi realizada com base no questionário de Godin e Shephard (11) que pretende marcar aspectos da actividade física semanal das crianças (do inglês leisure-time exercise). O valor obtido nas respostas é utilizado numa equação bem simples para estimar, numa unidade arbitrária, a actividade física realizada numa semana (ActFSemanal) tal que: ActFSemanal $=\left(9^{*}\right.$ número de episódios de actividade física intensa $)+\left(5^{*}\right.$ número de episódios de actividade física moderada $)+\left(3^{*}\right.$ número de episódios de actividade física ligeira).

Os valores 9, 5 e 3 correspondem a METs (equivalente metabólico) associados às qualidades das actividades descritas pelas crianças.

As respostas aos questionários foram obtidas por entrevistas directas às crianças por pessoas devidamente treinadas para o efeito.

Um dos problemas essenciais nos estudos de Epidemiologia Genética aplicados às Ciências do Desporto radica, necessariamente, na definição precisa de fenótipo, a que se associa, implicitamente, a sua obtenção com o menor erro possível (sobre esta matéria consultar Rice et al. - 32). Ora, na fórmula proposta no questionário de Godin e Shephard (11) é possível obter o mesmo valor de actividade física semanal com base em diferentes combinações das três parcelas. Daqui que tenhamos optado pelo estudo e análise de cada parcela, implicando necessariamente três fenótipos distintos, não só em frequências de episódios, mas também no que se refere à estimativa da sua intensidade, de 3, 5 e 9 METs. 
Neste sentido definimos, pois, três fenótipos: actividade física ligeira, actividade física moderada e actividade física intensa. São estes fenótipos, e não o total semanal proposto por Godin e Shephard (11), que serão objecto de análise da sua dependência genética, com base na amostra gemelar.

\section{Determinação da zigotia}

A determinação da zigotia ${ }^{2}$ foi efectuada com base num método indirecto (por motivos de ordem financeira), usando o questionário de zigotia (aplicado às mães) proposto por Peeters et al. (29), que apresentou a sua elevada validade concorrente face aos métodos de determinação de zigotia por DNA. A cotação da resposta das mães foi efectuada pelo primeiro autor. Passado um mês foi realizada uma nova cotação para avaliar a fiabilidade intra-observador na determinação da zigotia. O valor da estatística Kappa foi de 1 (100\% de classificação correcta) para os gémeos $\mathrm{MZ}$ e para os $\mathrm{DZ}$.

\section{Procedimentos estatísticos}

As análises prévias dos dados foram realizadas de acordo com a inspecção das distribuições, com base no teste de Kolmogorov-Smirnov, e a eventual localização de outliers. De seguida realizou-se o estudo das estatísticas descritivas habituais. Quando se lida com amostras gemelares de dimensão reduzida, como é o caso desta pesquisa, é necessário remover o efeito das covariáveis sexo e idade, por forma a obter fenótipos não "contaminados por estas variáveis". Nesta circunstância, é habitual recorrer-se à regressão múltipla e calcular os resíduos da regressão (sobre esta matéria ver Bouchard et al. - 3). De seguida foi efectuada a análise de variância no seio de cada grupo de gémeos para estimar os respectivos MSB (Mean Square Between) e MSW (Mean Square Within) nos resíduos da regressão e calcular, depois, os coeficientes de correlação intra-classe $(t)$ de acordo com as sugestões de Snedecor e Cochran (39), em que $\mathrm{t}_{\mathrm{MZ}}=\mathrm{MSB}_{\mathrm{MZ}} /\left(\mathrm{MSB}_{\mathrm{MZ}}+\mathrm{MSW}_{\mathrm{MZ}}\right)$; $\mathrm{t}_{\mathrm{DZ}}=\mathrm{MSB}_{\mathrm{DZ}} /\left(\mathrm{MSB}_{\mathrm{DZ}}+\mathrm{MSW}_{\mathrm{DZ}}\right)$. Com base nos valores do coeficiente de correlação intra-classe foram obtidas as estimativas de heritabilidade para os três fenótipos. Foi usado o software SYSTAT 10 em todos os cálculos.

\section{RESULTADOS E DISCUSSÃO}

É provável que a interpretação e alcance dos resultados desta pesquisa sejam condicionados pelo seguinte conjunto de aspectos, que convém ter sempre presente:

- O primeiro prende-se, necessariamente, com matérias da validade do questionário, uma vez que é difícil inventariar, de modo suficientemente rigoroso e válido, a actividade física de crianças. Ora o questionário de Godin e Shephard, apesar de pretender estimar, de forma objectiva, a narração subjectiva dos padrões distintos de actividade física de crianças, marcados que são por intensidades diversas e número de episódios, tem revelado validade concorrente moderada, relativamente a outros métodos $(25,30,35)$. Não obstante o questionamento de Scerpella et al. (36), relativamente a alguma inconsistência do questionário quando usado em meninas pré-pubertárias, a informação mais consistente sugere segurança na sua utilização, não deixando contudo de evidenciar a necessidade do recurso, associado, de outras técnicas mais objectivas (ver por exemplo 7 e 27) para marcar a diversidade e variabilidade da actividade física de crianças.

- O segundo ponto prende-se com a fiabilidade das respostas das crianças, dada a dificuldade que, às vezes, têm de recordar-se das actividades físicas realizadas durante uma semana. Este é um problema bem conhecido e identificado na literatura da especialidade ( 25 e 35). Contudo, também é importante salientar que autores como Sallis et al. (35) mostraram estimativas de fiabilidade situadas entre 0.69 e 0.96 para o questionário de Godin e Shephard (11) aplicado a crianças e jovens dos 11 aos 16 anos. Outros autores evidenciaram resultados situados entre 0.70 e 0.90 em pesquisas sobre actividade física diária de crianças dos 6 aos 10 anos de idade a quem foi aplicado este questionário $(19,21,24)$. Esta consistência nos valores da fiabilidade atribui segurança àquilo que é reportado pelas crianças, relativamente à sua actividade física semanal.

- O terceiro aspecto prende-se, obrigatoriamente, com a classificação dos gémeos pela diferente zigotia. Está bem estabelecido na literatura a sequencialidade da sua determinação, sobretudo 
com recurso a exame placentário e a marcadores de DNA (40). Contudo, também está bem estabelecido na literatura de Epidemiologia Genética o recurso a métodos indirectos, normalmente por questionário às mães, e que têm sido continuamente validados por concordância de exame de marcadores de DNA (ver, por exemplo, 6). Dado que na pesquisa presente foi sempre o mesmo sujeito a efectuar as cotações das respostas das mães, e porque já tinha sido anteriormente testada a sua concordância de classificação (24), é de esperar um erro diminuto a desprezível de má classificação gemelar.

- É praticamente inexistente a investigação acerca dos efeitos genéticos na actividade física de gémeos ou irmãos deste intervalo de idade. Uma busca nas bases de dados SportDiscus e Medline revelou-se infrutífera. O texto internacional (na realidade um livro) de revisão sobre a matéria "genetics of fitness and physical performance" da autoria de Bouchard et al. (3) salienta a raridade de pesquisa neste intervalo de idade, se excluirmos a investigação sobre aspectos do temperamento, do fidgeting e da insuficiência de atenção induzida por hiper-actividade (sobre este último ponto ver o excelente texto editado por Levy e Hay (18).

Os resultados obtidos nos diferentes fenótipos marcadores de níveis e frequências distintas de actividade física das crianças estão na Tabela 1.

Tabela 1: Valores médios \pm desvios-padrão $(M \pm D p$ ), mínimo e máximo nas diferentes categorias de actividade física dos gémeos agrupados exclusivamente por zigotia.

\begin{tabular}{c|l|cc}
\multicolumn{2}{l|}{ Tipo de actividade física } & $M \pm D p$ & Mínimo-Máximo \\
\hline MZ & Actividade física ligeira & $19.02 \pm 4.34$ & $6.00-21.00$ \\
\hline & Actividade física moderada & $20.68 \pm 10.32$ & $0.00-35.00$ \\
\hline & Actividade física intensa & $25.98 \pm 16.27$ & $0.00-63.00$ \\
\hline$D Z$ & Actividade física ligeira & $16.14 \pm 6.30$ & $3.00-21.00$ \\
\hline & Actividade física moderada & $21.34 \pm 11.89$ & $0.00-35.00$ \\
\hline & Actividade física intensa & $28.67 \pm 19.85$ & $0.00-63.00$
\end{tabular}

Os valores apresentados na Tabela 1 indicam a existência de uma enorme variabilidade inter-individual nos níveis e frequência de actividade física semanal, quer nos gémeos monozigóticos, quer nos dizigóticos. Esta variabilidade é indicada pelos valores bastante elevados dos desvios-padrão e pela diferença entre os valores mínimos (que são de zero nalguns casos) e os valores máximos. A variabilidade é elevada, sobretudo, nas frequências de actividade física moderada e intensa. De facto, verifica-se que os valores dos desvios-padrão são mais elevados e o mesmo ocorre para as diferenças entre os valores mínimos e máximos.

Estes dados sugerem a existência de crianças que podem ser classificadas como muito activas, envolvendo-se em esforços que exigem grandes dispêndios energéticos, e crianças inactivas, pouco dadas a actividades que exijam esforços com dispêndio energético acima dos valores de repouso. Infelizmente, não conhecemos valores de corte para a avaliação da actividade física através deste questionário que permitam uma classificação mais precisa, e que ajudaria a entender, de forma mais adequada, o padrão distinto de actividade física das crianças.

Os resultados da análise da regressão para calcular os resíduos por forma a obter estimativas dos três fenótipos, independentes dos efeitos do sexo e da idade, mostraram valores de $\mathrm{R}^{2}$ distintos, e que variavam entre $8.8 \%$ e os $12.5 \%$ nos gémeos $\mathrm{MZ}$, e os $1 \%$ a $32 \%$ nos gémeos DZ. Como bem referem Bouchard et al. (3), esta é uma necessidade essencial para obter um fenótipo "mais puro" e tradutor daquilo que se procura mapear em termos de diferenças inter-individuais, independente que é, tanto quanto possível, de variáveis concomitantes. De facto, se pensarmos que a actividade física é entendida como qualquer movimento produzido pelos músculos esqueléticos e que resulta em dispêndio energético para além do metabolismo de repouso, estamos diante de uma definição fenotípica que contém um espaço observacional demasiado extenso e indutor de alguns equívocos. Esta circunstância é bem ilustrada numa pesquisa recente (37) em que foi sentida a forte necessidade de definir três fenótipos com base em estimativas de dispêndio energético reportados a três dias: "inactividade" (que incluía ver TV, comer, dormir, higiene diária, fazer a comida, conduzir o automóvel, andar devagar), actividade física moderada a vigorosa e actividade física total. 
Num sentido convergente encontram-se as reflexões de Rice et al. (32) relativamente à necessidade de definição precisa de um qualquer fenótipo. É que somente a partir desta operacionalização, e na presença de estimativas moderadas a elevadas de heritabilidade, se torna possível investigação mais profunda com base em metodologias de Linkage ou Quantitative Trait Loci (ver, por exemplo, 3 e 31). No estudo que temos em mãos, foi preocupação dos autores tentar distinguir, claramente, aspectos distintos da actividade física - ligeira, moderada e intensa. É evidente que o sinal fenotípico (número de episódios semanais de actividade física de diferentes intensidades) que se analisa quantitativamente nesta pesquisa é, também, contaminado pela presença de erros de medição/avaliação. Ora, aqui, os valores obtidos pelas estimativas de fiabilidade são equivalentes aos reportados na literatura, o que permite, num certo sentido, as inferências com algum grau de confiança, ainda que sempre temperadas pela circunstância da amostra disponível ser de dimensão reduzida.

Na Tabela 2 estão disponíveis as estatísticas necessárias ao cálculo do coeficiente de correlação intra-classe.

Tabela 2: Resultados da análise de variância no seio de cada zigotia (MSB=Mean Square Between; MSW=Mean Square Within; $t=$ coeficiente de correlação intra-classe]

\begin{tabular}{l|l|c|c|c}
\multicolumn{2}{l|}{ Tipo de actividade física } & MSB & MSW & $t$ \\
\hline MZ & Actividade física ligeira & 37.886 & 0.205 & 0.995 \\
& Actividade física moderada & 179.502 & 30.682 & 0.854 \\
\hline & Actividade física intensa & 335.547 & 31.296 & 0.915 \\
\hline DZ & Actividade física ligeira & 58.725 & 12.418 & 0.825 \\
\hline & Actividade física moderada & 217.662 & 41.855 & 0.838 \\
\hline & Actividade física intensa & 551.878 & 141.226 & 0.796
\end{tabular}

Nos fenótipos considerados, é evidente uma maior variação intra-par nos gémeos DZ relativamente aos gémeos $M Z$, sobretudo na actividade física ligeira e intensa. Estes resultados procuram traduzir, necessariamente, uma maior homogeneidade de prática de actividade física nos gémeos $\mathrm{MZ}$ em detrimento dos gémeos DZ. Contudo, na actividade física ligeira os resultados são praticamente iguais (30.682 nos gémeos $\mathrm{MZ}$ e 41.855 nos gémeos $\mathrm{DZ}$ ).
Os valores dos coeficientes de correlação intra-classe são todos elevados, não se vislumbrando, desde logo, um forte efeito genético a governar as diferenças de valores nos níveis de actividade física, pela circunstância do valor dos $t_{\mathrm{DZ}}$ ser sempre mais de metade do valor do $t_{\mathrm{MZ}}$. As estimativas dos efeitos genéticos, e do envolvimento, nas diferenças inter-individuais nos três níveis ou categorias de actividade física estão na Tabela 3.

Tabela 3: Estimativas, em termos de percentagem de variância, dos efeitos genéticos $\left(h^{2}\right]$, do envolvimento comum $\left[c^{2}\right]$ e envolvimento único $\left[e^{2}\right]$ nos três fenótipos marcadores da actividade física.

\begin{tabular}{l|c|c|c} 
Tipo de actividade física & $\mathrm{h}^{2}$ & $\mathrm{c}^{2}$ & $\mathrm{e}^{2}$ \\
\hline Actividade física ligeira & $34.0 \%$ & $65.5 \%$ & $0.5 \%$ \\
\hline Actividade física moderada & $3.2 \%$ & $82.2 \%$ & $14.6 \%$ \\
\hline Actividade física intensa & $23.8 \%$ & $67.7 \%$ & $8.5 \%$
\end{tabular}

Destes resultados emergem dois pontos que reputamos de essenciais:

- O primeiro prende-se com o facto, indesmentível, das crianças serem normalmente activas, embora também seja mais do que evidente que se verificam diferenças substanciais nos seus níveis de actividade física, qualquer que seja a categoria utilizada para marcar, não somente a sua intensidade, como também a sua frequência e duração (ver por exemplo Maia et al. - 24). Os efeitos genéticos estimados são irrelevantes para a actividade física moderada $(3,2 \%)$, e baixos para a actividade física ligeira $(34.0 \%)$ e intensa (23.8\%). Ainda que a magnitude de $\mathrm{h}^{2}$ seja baixa, é importante considerar que cerca de $1 / 4$ da variância total na heterogeneidade dos valores de actividade física, sobretudo a intensa, é governada por diferenças genéticas entre sujeitos. É claro da Figura 1, a complexidade de factores que medeiam a influência dos genes nos níveis de actividade física. Diferenças genéticas produzem, necessariamente, diferenças de comportamento, enquanto expressão clara da personalidade dos sujeitos. Ora, há estudos que mostram que aspectos da personalidade, sobretudo tendências 
distintas para evidenciar comportamentos mais activos (i.e., os seus temperamentos) mostram influências genéticas marcantes (ver, por exemplo, 3). Em estudos com amostras mais vastas de gémeos, de idades distintas, e com outros marcadores da actividade física foram reportadas estimativas de heritabilidade que rondavam os $50 \%$ $(14,24,27)$. Daqui que a magnitude dos valores constantes da Tabela anterior possa ser reflexo, não só do procedimento para marcar as categorias distintas de actividade física, mas também da dimensão da amostra. Emerge, pois, a exigência de replicação da pesquisa com uma amostra de maior dimensão, e que recorra a outros métodos de avaliação da actividade física (embora esta tarefa não seja necessariamente fácil de realizar neste intervalo de idade (para mais sugestões sobre delineamentos ver Oliveira e Maia - 27).

- O segundo ponto prende-se com os valores moderados a elevados do envolvimento comum partilhado no seio da família e outros significantes, e que variam entre $66 \%$ para a actividade física ligeira e $80 \%$ para a actividade física intensa. Estes resultados salientam a importância substancial do papel dos progenitores na construção de estilos de vida activa nas crianças, e desde muito cedo. Esta influência nos níveis de semelhança familiar é clara na noção de socialização através do desporto, ou no paradigma da aprendizagem social (ver Greendorer e Lewco - 13). Na referida investigação, realizada em famílias nucleares, é bem evidente o papel de modelo do pai, amigos e professores no envolvimento desportivo de crianças dos dois sexos dos 8 aos 13 anos de idade. No mesmo sentido vão os resultados da pesquisa de Freedson e Evenson (10) acerca da agregação familiar relativa à actividade física de famílias nucleares, onde é mostrado que pais activos tendem a ter filhos mais activos (67\% pai-filho, $73 \%$ mãe-filho) do que pais inactivos ou pouco activos. Também Moore et al. (26) salientaram que quando o pai é activo, a propensão para as crianças serem activas é 3.4 vezes superior à de outras cujo pai é inactivo. Quando a mãe é activa, a propensão passa para 2 vezes superior, e quando os dois progenitores são activos, a propensão é 7.2 vezes superior à de outras crianças cujos pais sejam muito pouco activos.

\section{CONCLUSÕES}

Há que referir diversos pontos: o primeiro remetenos para a necessidade de prestar uma maior atenção a aspectos das diferenças entre sujeitos, no que respeita à sua actividade física e à necessidade da sua interpretação a partir de um olhar que case biologia com sócio-psicologia e ambiente físico onde vivem as populações; o segundo implica a atenção para uma maior dependência génica dos níveis mais baixos de actividade física do que os níveis mais intensos; o terceiro, para salientar que, em crianças, cerca de 1/4 da variação dos seus níveis de actividade física está dependente das suas diferenças genéticas; o quarto, para manifestar a grande influência do envolvimento comum das crianças, sobretudo do seio familiar, remetendo para os pais, amigos e professores um fortíssimo papel pedagógico na implementação de hábitos moderados a intensos de actividade física que se associam à promoção de estilos de vida mais saudáveis.

\section{Notas \\ ${ }^{1}$ Chamamos a atenção do leitor para a consulta do livro de texto essencial no domínio da pesquisa gemelar da autoria de Neale e Cardon (1993) cujo título é o seguinte: Methodology for genetic studies of twins and families. Michael Neale (neale@psycho.psi.vcu.edu) disponibiliza gratuitamente o softwa- re Mx para realizar as análises contidas no livro. Consultar a sua página $h t t p: / / g r i f f i n . v c u . e d u / m x$. \\ ${ }^{2}$ A determinação da zigotia refere-se à possibilidade de classifi- car os pares de gémeos em monozigóticos ou idênticos e dizi- góticos ou fraternos.}

\section{Agradecimento}

Os autores querem expressar o seu profundo agradecimento à Direcção Regional de Educação Física e Desporto da Região Autónoma dos Açores, concretamente ao Dr. Rui Santos, por ter financiado esta pesquisa.

\section{CORRESPONDÊNCIA}

José António Ribeiro Maia

Universidade do Porto

Faculdade de Ciências do Desporto

e de Educação Física

Laboratório de Cineantropometria e

Gabinete de Estatística Aplicada

Rua Dr. Plácido Costa, 91

4200.450 Porto, Portugal

jmaia@fcdef.up.pt 


\section{BIBLIOGRAFIA}

1. Beunen, G.P.; Malina, R.M.; Van't Hoft, M.A.; Simons, J.; Ostyn, M.; Renson, R.; Van Gorren, D. (1988). Adolescent growth and motor performance: a longitudinal study of Belgian boys. Champaign: Human Kinetics.

2. Blair, S.N.; Kampert, J.B.; Kohl, H.W.; Barlow C.E.; Macera, C.A.; Paffenbarger, R.S.; Gibbons, L.W. (1996). Influences of cardiorespiratory fitness and other precursors on cardiovascular disease and all-cause mortality in men and women. Journal of the American Medical Association, 276 (3): 205-210

3. Bouchard, C.; Malina, R.; Péruse, L. (1997). Genetics of fitness and physical performance. Champaign: Human Kinetics.

4. Bouchard, C.; Shephard, R. (1994). Physical activity, fitness and health: the model and key concepts. Physical Activity, Fitness and Health: International Proceedings and Consensus Statement. Champaign Il: Human Kinetics Publishers.

5. Caspersen, C.; Powell, K.; Christenson, G. (1985). Physical activity, exercise, and physical fitness: definitions for healthrelated research. Public Health Reports, 100(2): 126-131

6. Chen W.J.; Chang, H.W.; Wu, M.Z. (1999). Diagnosis of zygosity by questionnaire and polimarker polymerase chain reaction in young twins. Behavioural Genetics 29(2):115-123.

7. Ekelund, U.; Sjostrom, M.; Yngve, A.; Poortvliet, E.; Nielsson, A.; Froberg, K.; Wedderkopp, N.; Westerterp, K. (2001). Physical activity assessed by activity monitors and doubly labelled water in children. Med. Sci. Sports Exercise, 33: 275-281.

8. Falconer, D.S. (1990). Introduction to quantitative genetics. Essex: Longman Scientific \& Technical.

9. Fontaine, E.; Saward, R.; Tremblay, A.; Després, J.P.; Proehlmen, E.; Bouchard, C. (1985). Resting metabolic rate in monozigotic and dizygotic twins. Acta Genet. Med. Gemellos, 334: 41-47.

10. Freedson, P.; Evenson, S. (1991). Familial aggregation in physical activity. Research Quarterly for Exercise and Sport, 62(4): 384-389.

11. Godin, G.; Shephard, R. (1985). A simple method to assess exercise behaviour in the community. Can. J. Appl. Sport. Sci., 19: 141-146.

12. Gottlieb, N.H.; Baker, J.A. (1986). The relative influence of health beliefs, parental and peer behaviours and exercise program participation on smoking, alcohol use and physical activity. Soc. Sci. Med. 22, 9: 915-927.

13. Greendorfer, S.; Lewko, J. (1978). Role of family members in sport socialization of children. Research Quarterly for Exercise and Sport, 49(2): 146-153.

14. Kaprio, J.; Koskenvuo, M.; Sarna, S. (1981). Cigarette smoking, use of alcohol, and leisure-time physical activity among same-sexed adult male twins. In Twin Research 3: Epidemiological and Clinical Studies. New York: Allan R. Liss, Inc., 37-46.

15. Kemper, H. (1995). The Amsterdam growth study. A longitudinal analysis of health fitness, and lifestyle. Champaign: Human Kinetics.

16. Khoury, M.J.; Beaty, B.; Cohen, B.H. (1993). Fundamentals of genetic epidemiology. New York, Oxford: University Press.

17. Lau, R.R.; Quadrel, M.J.; Hartman, K.A. (1990). Development and change of young adult's preventive health beliefs and behaviour: influence from parents and peers. Journal of Health and Social Behavior, 31: 240-259.
18. Levy, F.; Hay, D. (2001). Attention, genes and ADHD. Sussex Brunner-Routledge.

19. Lopes, V. P.; Monteiro, A. M.; Barbosa, T.; Magalhães, P. M.; Maia, J. A. R. (2001). Actividade física habitual em crianças pré-púberes. Diferenças entre rapazes e raparigas. Revista Portuguesa de Ciências do Desporto, 1(3): 53-60.

20. Lynch, M.; Walsh, B. (1998). Genetic analysis of quantitative traits. Massachusetts: Sinnauer Associates, Inc. Publishers.

21. Magalhães, M. (2001). Padrão de actividade física - Estudo em crianças de ambos os sexos do $4^{\circ}$ ano de escolaridade. Dissertação de Mestrado. Faculdade de Ciências do Desporto e de Educação Física da Universidade do Porto (não publicada).

22. Maia, J. (1996). Avaliação da aptidão física. Uma abordagem metodológica. Horizonte 73(XIII)Dossier

23. Maia, J.; Lopes, V.; Morais, F. (2001). Actividade física e aptidão física associada à saúde - Um estudo de epidemiologia genética em gémeos e suas famílias realizado no arquipélago dos Açores. Porto: Faculdade de Ciências do Desporto e de Educação Física da Universidade do Porto e Direcção Regional de Educação Física e Desporto da Região Autónoma dos Açores.

24. Maia, J.; Thomis, M.; Beunen, G. (2002). Genetic factors in physical activity levels. A twin study. American Journal of Preventive Medicine, 23: 87-91.

25. Montoye, H.R.; Kemper, C.G.; Saris, W.M.; Washburn, R.A. (1996). Measuring physical activity and energy expenditure. Champaign: Human Kinetics.

26. Moore, L.; Lombardi, D.; White, M.; Campbell, J.; Oliveria, S.; Ellison, C. (1991). Influence of parents' physical activity levels on activity levels of young children. The Journal of Paediatrics, 118(2): 215-219.

27. Oliveira, M.M.C.; Maia, J.A.R. (2002). Avaliação multimodal da actividade física. Um estudo exploratório em gémeos monozigóticos e dizigóticos. Porto: Faculdade de Ciências do Desporto e de Educação Física da Universidade do Porto.

28. Pate, R.R.; Pratt, M.; Blair, R, S.; Haskell, W.L.; Macera, C.A.; Bouchard, C.; Buchner, D.; Ettinger, W.; Heath, G.W.; King, A.C.; Kriska, A.; Leon, A.S.; Matcus, B.H.; Morris, J.; Paffenbarger, R.S.; Patrick, K.; Pollock, M.L.; Rippe, J.M.; Sallis, J.; Wilmore, J.H. (1995). Physical activity and public health. A recommendation from the centers for disease control and prevention and the American College of Sports Medicine. Journal of the American Medical Association, 273, 5:

402-407.

29. Peeters, H.; Van Gestel, S.; Vlietinck, R.; Derom, R. (1998). Validation of a telephone zygosity questionnaire in twins of known zygosity. Behavioural Genetics, 28: 159-163.

30. Pereira, M.; Fitzgerard, S.; Greg, E.; Joswiak, M.; Ryan, W.; Suminski, R.; Utter, A.; Zmuda, J. (1998). A collection of physical activity questionnaires for health-related research. Medicine and Science in Sports Exercise, 29(6): 117-145.

31. Rao, D.C.; Province, M.A. (2001). Genetic dissection of complex traits. New YorK: Academic Press.

32. Rice, J.P.; Saccone, N.L.; Rasmussen, E. (2001). Definition of the phenotype. In DC Rao, MA Province (eds) Genetic dissection of complex traits. New York: Academic Press, 69-76.

33. Rossow, I.; Rise, J. (1994). Concordance of parental and adolescent health behaviours. Soc. Sci. Med., 38, 9: 1299-1305.

34. Rowland, T.W. (1998). The biological basis of physical activity. Medicine \& Science in Sports and Exercise, 30, 3: 392-399. 
35. Sallis, J.; Nader, P.; Broyles, S.; Berry, C.; Elder, J.; McKenzie, T.; Nelson, J. (1993). Correlates of physical activity at home in Mexican-American and AngloAmerican preschool children. Health Psychology Official Journal of the Division of Health Psychology, American Psychological Association, 12(5): 390-398.

36. Scerpella, J.A.; Tuladhar, P.; Kamaley, J.A. (2002). Validation of the Godin-Shephard questionnaire in prepubertal girls. Medicine and Science in Sport and Exercise, 5: 845-850.

37. Simonen, R.L.; Péruse, L.; Rankinen, T.; Rice, T.; Rao, D.C.; Bouchard, C. (2002). Familial aggregation of physical activity levels in the Québec Family Study. Medicine and Science in Sport and Exercise, 34(7): 1137-1142.

38. Simons, J.; Beunen, G.P.; Renson, R.; Claessens, A.L.M.; Vanrensel, B.; Lefevre, J.A.V. (1990). Growth and fitness of Flemish girls. The Leuven growth study. Champaign: Human Kinetics

39. Snedecor, G.W.; Cochran, W.G (1991). Statistical methods. $8^{\text {th }}$ edition. Iowa State University Press.

40. Vlietinck, R.F. (1986). Determination of the zygosity of twins. Dissertação de doutoramento. Centro de Genética Humana. Lovaina: Universidade Católica de Lovaina (não publicado). 